\title{
The relationship between QDASH scale and clinical, electrophysiological findings in carpal tunnel syndrome
}

\author{
Yasemin Eren ${ }^{1, A-F}$, Neşe Güngör Yavasoglu ${ }^{2, B-D, F}$, Selim Selcuk Comoglu, ${ }^{2,-F}$ \\ 1 Department of Neurology, Diskapi Yildirim Beyazit Education and Research Hospital, Ankara, Turkey \\ ${ }^{2}$ Neurology Clinic, Ankara Diskapi Yildirim Beyazit Education and Research Hospital, Turkey \\ A - research concept and design; $\mathrm{B}$ - collection and/or assembly of data; $\mathrm{C}$ - data analysis and interpretation; \\ $D$ - writing the article; $E$ - critical revision of the article; $F$ - final approval of the article
}

\section{Address for correspondence \\ Yasemin Eren \\ E-mail: yeren.72@hotmail.com}

Funding sources

None declared

\section{Conflict of interest}

None declared

Received on June 18, 2016

Reviewed on August 27, 2016

Accepted on December 20, 2016

\section{Abstract}

Background. Carpal tunnel syndrome (CTS) occurs as a result of compression of the median nerve at the wrist. The Quick Disabilities of the Arm, Shoulder, and Hand (QuickDASH) questionnaire is a selfadministered region-specific outcome instrument which measures symptom severity and functional status.

Objectives. The aim of this study was to evaluate the clinical and electrophysiological relationship with QDASH scale in CTS

Material and methods. The study included 99 females and 22 males in total out of 121 idiopathic CTS patients with the mean age of $47.9 \pm 9.5$ years. Patients were divided clinically and electrophysiologically into 2 groups as severe and mild based on modified criteria defined by Italian CTS working group. Pain severity was evaluated by visual analog scale (VAS). Patients were evaluated functionally by QDASH scale and the relationship between clinical and electrophysiological effect intensity (degree) was examined.

Results. QDASH scores were found significantly high in female patients, in patients with long disease duration (6 years and more), patients with clinically severe symptoms, and the ones with positive phalen test in both hands. Statistically significant positive relationship was found between QDASH scores, disease duration and clinical severity. However, no relationship was found between electrophysiological severity and QDASH. A mild and positive correlation was observed among disease duration, clinical severity and VAS. A small and positive correlation was detected between VAS and QDASH.

Conclusions. Although electrophysiological findings were prioritized in the follow-up and treatment strategies of CTS patients, clinical and patient-oriented assessment scales should be dealt together. Despite the electrophysiological findings, we believe that individual differences are effective in clinical and functional capacity. We conclude that since QDASH scale has a simple applicability in a short time, it can be used for assessing the symptom severity and disability of patients with CTS.

Key words: carpal tunnel syndrome, VAS, electrophysiology, QDASH

DOI

10.17219/acem/67947

\section{Copyright}

Copyright by Author(s)

This is an article distributed under the terms of the

Creative Commons Attribution Non-Commercial License

(http://creativecommons.org/licenses/by-nc-nd/4.0/) 


\section{Introduction}

Carpal tunnel syndrome (CTS) occurs as a result of compression of the median nerve at the wrist, and this constitutes about $90 \%$ of all entrapment neuropathies. CTS prevalence varies between $2 \%$ and $3 \%$ in the general population. ${ }^{1}$ It is seen 3 times more often in women than in men. It is most commonly observed in women between the ages of 40 and 60 years. $^{2}$

The most common symptoms are pain and paresthesia in the hand. Paresthesia is evident in the first 3 fingers and the radial side of the $4^{\text {th }}$ finger. The symptoms get worse at night and patients try to reduce the physical disturbance by shaking their hands. ${ }^{1}$ Sensory symptoms are also felt in areas other than the median nerve innervation and the whole hand is affected. ${ }^{3}$ In addition, pain and paresthesia may spread to the forearm and shoulder; this phenomenon has been associated with central sensitization. ${ }^{4,5}$ Some of the patients feel that their hand is swollen, even if it is not, and their complaints are evident in the morning. As the CTS progresses, paresthesia starts to occur also in the morning. In a further period, muscle weakness in the thenar area and atrophy occur. The thumb cannot do abduction and opposition. In a small number of cases, there may be findings of autonomic sympathetic nerve involvement in median nerve distribution area. ${ }^{6}$ Continuous wrist extension and flexion, and repetitive hand movements aggravate the symptoms.

Paresthesia occurs in median nerve innervation area with the percussion of median nerve at the wrist (Tinel's sign) or passive wrist flexion (Phalen's maneuver). Although radiological methods such as ultrasound and magnetic resonance imaging (MRI) are used for diagnosis, electrophysiological studies are the gold standard.?

The Disabilities of the Arm, Shoulder and Hand (DASH) scale was developed by Hudak et al. in 1996 to evaluate the symptoms and physical functions of the patients with pathology of the upper extremities, and it was found to be reliable in evaluating CTS results. ${ }^{8}$ The Quick Disabilities of Arm, Shoulder and Hand (QDASH) scale is a shortened and improved version of DASH, and the validity and reliability of Turkish version was shown in patients with CTS., ${ }^{9,10}$ In this study, we aim to assess the patients with CTS by QDASH (functionally) and to examine the relationship between clinical and electrophysiological findings.

\section{Material and methods}

In this study, 121 patients with idiopathic CTS were evaluated according to the CTS diagnostic criteria of the American Academy of Neurology (AAN) ${ }^{11}$ Patients with neurological, endocrinological, orthopedic, rheumatologic and upper extremity surgery history were excluded. The demographic data of the patients is shown in Table 1. Patients were examined in 2 groups as mild and severe (Table 2, 3) according to clinical and electrophysiological findings
Table 1. Demographic characteristics

\begin{tabular}{|c|c|c|}
\hline $\begin{array}{l}\text { Characteristics } \\
\text { of patients }\end{array}$ & $\mathrm{n}=121$ & $\%$ \\
\hline $\begin{array}{l}\text { Age } \\
\text { mean } \pm S D\end{array}$ & $47.9 \pm 9.5$ & - \\
\hline $\begin{array}{l}\text { Gender } \\
\text { female } \\
\text { male }\end{array}$ & $\begin{array}{l}99 \\
22\end{array}$ & $\begin{array}{l}81.8 \\
18.2\end{array}$ \\
\hline $\begin{array}{l}\text { Occupation } \\
\text { worker } \\
\text { officer } \\
\text { housewife }\end{array}$ & $\begin{array}{c}42 \\
7 \\
72\end{array}$ & $\begin{array}{r}34.7 \\
5.8 \\
59.5\end{array}$ \\
\hline $\begin{array}{l}\text { Hand dominance } \\
\text { right } \\
\text { left }\end{array}$ & $\begin{array}{c}114 \\
7\end{array}$ & $\begin{array}{c}94.2 \\
5.8\end{array}$ \\
\hline $\begin{array}{l}\text { Education } \\
\text { illiterate } \\
\text { primary school } \\
\text { secondary school } \\
\text { high school } \\
\text { university }\end{array}$ & $\begin{array}{l}10 \\
66 \\
16 \\
19 \\
10\end{array}$ & $\begin{array}{r}8.2 \\
54.5 \\
13.2 \\
15.7 \\
8.4\end{array}$ \\
\hline $\begin{array}{l}\text { Duration of disease } \\
<1 \text { year } \\
2-5 \text { years } \\
6-9 \text { years } \\
\geq 10 \text { years }\end{array}$ & $\begin{array}{c}55 \\
47 \\
9 \\
10\end{array}$ & $\begin{array}{c}45.5 \\
38.8 \\
7.4 \\
8.3\end{array}$ \\
\hline
\end{tabular}

Table 2. Clinical classification in CTS

\begin{tabular}{|l|l|l|}
\multicolumn{2}{|c|}{ Severity } & \multicolumn{1}{|c|}{ Clinical history and objective findings } \\
\hline \multirow{2}{*}{ Mild } & 0 & asymptomatic \\
& 1 & only night paresthesia \\
\hline \multirow{2}{*}{ Severe } & 2 & night and day paresthesia \\
\hline & 3 & sensory loss \\
\cline { 2 - 3 } & 5 & $\begin{array}{l}\text { in the median innervated thenar muscles atrophy } \\
\text { and/or weakness }\end{array}$ \\
\hline
\end{tabular}

Table 3. Electrophysiological classification of CTS according to median nerve conduction study findings

\begin{tabular}{|c|c|c|}
\hline \multicolumn{2}{|c|}{ Severity } & Electrophysiological findings \\
\hline \multirow{3}{*}{ Mild } & 0 & negative CTS: normal findings \\
\hline & 1 & $\begin{array}{l}\text { minimal CTS: in the palm-wrist segment abnormal } \\
\text { sensory conduction study or abnormality } \\
\text { in } 4^{\text {th }} \text { f. comparative tests }\end{array}$ \\
\hline & 2 & $\begin{array}{l}\text { mild CTS: abnormal sensory transduction } \\
\text { in finger }(1,2,3) \text {-wrist segment }\end{array}$ \\
\hline \multirow{3}{*}{ Severe } & 3 & $\begin{array}{l}\text { moderate CTS: abnormal sensory transduction } \\
\text { in finger }(1,2,3) \text {-wrist segment and prolonged } \\
\text { motor distal latency }\end{array}$ \\
\hline & 4 & $\begin{array}{l}\text { severe CTS: absence of SNAP in the finger }(1,2,3) \text {-wrist } \\
\text { segment prolonged motor distal latency }\end{array}$ \\
\hline & 5 & extreme CTS: absence of CMAP and SNAP \\
\hline
\end{tabular}

CTS - carpal tunnel syndrome; SNAP - sensory nerve action potential; CMAP - compound muscle action potential; finger $(1,2,3)$-thumb, index and middle finger 
on the basis of modified criteria that were defined by Italian CTS working group. ${ }^{12-14}$ Pain severity was evaluated by Visual Analogue Scale (VAS). Patients were examined functionally by QDASH scale and the relationship between clinical and electrophysiological response severity was examined. A neurological examination of the patients, electrophysiological examination and QDASH disability scale were conducted by 2 neurologists. Additionally, patients of treatments were recorded according to the disease duration. There were 55 patients whose duration of disease was $>1$ year. Out of that group, 22 patients were treated conservatively and the other 23 patients were not treated because they were newly diagnosed with CTS. The group of 47 patients whose duration of the disease was 2-5 years was only conservatively treated, e.g., by teaching patients how to use their hands in daily activities and how to use a splint. Patients whose duration of disease was 6-9 years and over 10 years were treated with medical, physical and kinesio therapies, and they also underwent surgery.

The study was carried out in accordance with the Declaration of Helsinki. Patients were informed about the details of the study. The study was approved by the local ethics committee of Diskapı Yıldırım Beyazıt Training and Research Hospital (19/24-2015).

QDASH is a shortened version of the DASH scale that was developed to measure the physical symptoms and function of patients with upper extremity pathology. The questionnaire consists of 2 scales; one of them is the disability and symptoms scale with 11 items, and also an optional scale related to working, sport and playing instruments. There are 5 answer choices to each question. One point is given for the mildest symptom or functional status, 5 points for the most severe symptom or functional status. A score is calculated by the following formula: total points of $n / n$ ) $-1 \times 25$ (where $n$ is the total number of questions) and if there is more than 1 unanswered questions, the QDASH score cannot be calculated. The score varies from 0 to 100 . Our patients did not answer the questions in the optional scale because of the sociocultural situation, which is why the scale was not evaluated.

Electrophysiological examination was done by DantecKeypoint (Alpine Biomed ApS., Skovlunde, Denmark) using surface electrodes and the temperature of extremity was kept above $31^{\circ} \mathrm{C}$. The median sensorial conduction velocity in the $2^{\text {nd }}$ finger-wrist segment and ulnar nerve sensorial conduction velocity in $5^{\text {th }}$ finger-wrist segment were studied antidromically. For median nerve sensorial conduction, velocity $\geq 50 \mathrm{~ms}$ for sensory nerve action potential (SNAP) and amplitude $\geq 20 \mu \mathrm{v}$ were considered normal. For ulnar nerve sensory conduction, velocity $\geq 50 \mathrm{~ms}$, SNAP amplitude $\geq 17 \mu$ vere considered normal. Also, it was interpreted in favor of CTS that in the $4^{\text {th }}$ fingerwrist, segment median and ulnar sensory peak latency difference was longer than $0.5 \mathrm{~ms}^{15}$

The median nerve motor conduction velocity was recorded from the abductor pollicis brevis muscle. It was stimulated in $8 \mathrm{~cm}$ proximally from the active electrode
Table 4. The distribution of QDASH scores according to clinical and electrophysiological data

\begin{tabular}{|c|c|c|}
\hline Characteristics of patient & QDASH & p-value \\
\hline $\begin{array}{l}\text { Gender } \\
\text { female } \\
\text { male }\end{array}$ & $\begin{array}{l}52.5 \pm 20.1 \\
32.7 \pm 19.5\end{array}$ & $0.0001^{*}$ \\
\hline $\begin{array}{l}\text { Duration of disease } \\
<1 \text { year } \\
2-5 \text { years } \\
6-9 \text { years } \\
\geq 10 \text { years }\end{array}$ & $\begin{array}{c}43.3 \pm 22.4 \\
50.4 \pm 20.6 \\
64.3 \pm 7.2 \\
58.7 \pm 16.1\end{array}$ & $0.01^{*}$ \\
\hline $\begin{array}{l}\text { Phalen right } \\
\text { positive } \\
\text { negative }\end{array}$ & $\begin{array}{l}54.5 \pm 19.4 \\
39.3 \pm 21.1\end{array}$ & $0.0001^{*}$ \\
\hline $\begin{array}{l}\text { Phalen left } \\
\text { positive } \\
\text { negative }\end{array}$ & $\begin{array}{l}57.0 \pm 19.9 \\
41.1 \pm 19.8\end{array}$ & $0.0001^{*}$ \\
\hline $\begin{array}{l}\text { Tinel right } \\
\text { positive } \\
\text { negative }\end{array}$ & $\begin{array}{l}52.4 \pm 20.1 \\
43.0 \pm 22.0\end{array}$ & 0.01 \\
\hline $\begin{array}{l}\text { Tinel left } \\
\text { positive } \\
\text { negative }\end{array}$ & $\begin{array}{l}52.1 \pm 21.7 \\
45.8 \pm 20.5\end{array}$ & 0.10 \\
\hline $\begin{array}{l}\text { Clinical severity } \\
\text { mild } \\
\text { severe }\end{array}$ & $\begin{array}{c}45.9 \pm 20.6 \\
71.9 \pm 7.8\end{array}$ & $0.0001^{*}$ \\
\hline $\begin{array}{l}\text { EMG severity } \\
\text { mild } \\
\text { severe } \\
\text { right severe - left mild } \\
\text { left severe - right mild }\end{array}$ & $\begin{array}{l}45.4 \pm 18.3 \\
50.4 \pm 22.7 \\
60.0 \pm 15.1 \\
32.7 \pm 14.0\end{array}$ & 0.05 \\
\hline
\end{tabular}

${ }^{*} p<0.5$ is statistically significant.

and the antecubital fossa. Motor distal latency $<4.2 \mathrm{~ms}$, conduction velocity $\geq 50 \mathrm{~ms}$ and over, and median nerve compound muscle action potential (CMAP) amplitude $\geq 4 \mathrm{mV}$ were considered normal. Ulnar nerve was stimulated in $7 \mathrm{~cm}$ proximally from the active electrode, under and over the elbow and recorded from abductor digiti minimi muscle. For motor conduction velocity $\geq 49 \mathrm{~ms}$ was considered normal. The ulnar nerve CMAP $\geq 6 \mathrm{mV}$ was considered normal. ${ }^{15}$

\section{Statistical analysis}

All statistical analyses were performed using the Statistical Package for the Social Sciences (SPSS), v. 15.0 for Windows (SSPS; Chicago, USA). Descriptive values were stated as "number" and "percent". According to the data distribution, variables were defined as mean \pm standard deviation or median (min-max). At the end of the evaluation, categorical data was compared using $X^{2}$ test. According to the data distribution, to compare paired numerical data, the Mann-Whitney U-test or the Student's t-test were used. For the comparison of more than 2 pieces of data, the Kruskal-Wallis or the oneway ANOVA test were used. The relationship between the variables was tested by Pearson's or Spearman's correlation analysis, according to the distribution of the parameters. The significance level was set at $\mathrm{p}<0.05$. 


\section{Results}

This study included 99 females and 22 male patients (the mean age was $47.9 \pm 9.5$ years). CTS was found on 1 side in 24 patients, bilaterally in 97 patients. In total, CTS was detected electrophysiologically in 218 hands. QDASH values were found significantly high (Table 4) in female patients $(\mathrm{p}=0.0001)$, in patients whose duration of disease is $>6$ years $(\mathrm{p}=0.01)$, patients with severe clinical symptoms ( $\mathrm{p}<0.0001)$, and patients with positive Phalen's test in both hands $(\mathrm{p}=0.0001)$.

In female patients $(\mathrm{p}=0.02)$, in patients whose duration of the disease is $>6$ years $(\mathrm{p}=0.02)$ and in patients with positive Phalen's test on the right hand ( $p=0.01)$, with clinical $(p=0.02)$ and severe EMG findings $(p=0.01)$, VAS results were found significantly high.

In a correlation analysis, a statistically significant positive relationship was found between QDASH results, duration of the disease $(\mathrm{r}=0.30 ; \mathrm{p}=0.001)$, and clinical severity $(r=0.43 ; p=0.0001)$. Statistically significant positive mild relationship was found between VAS results, duration of the disease $(\mathrm{r}=0.28 ; \mathrm{p}=0.002)$ and clinical severity $(r=0.23 ; p=0.01)$. Statistically significant positive moderate relationship was found between severe clinical symptoms and EMG severity $(\mathrm{r}=0.27 ; \mathrm{p}=0.002)$.

\section{Discussion}

In this study, we examined the relationship between QDASH scale and clinical electrophysiological findings in CTS. As stated in the literature, CTS was found more often in female patients and in the dominant hand (about 94.4\% of the patients were right-handed). ${ }^{1,2,15}$ Although CTS is usually bilateral, both clinically and electrodiagnostically, especially in idiopathic cases, the dominant hand may be affected more severely. In patients with a positive bilateral Phalen's test and a positive Tinel's test on the right, QDASH scores were high. The sensitivity of the Phalen's test ranged from 67 to $83 \%$ and its specificity from 40 to $98 \%$. The sensitivity of the Tinel's test ranged from 48 to $73 \%$, and its specificity from 30 to $94 \% .{ }^{16}$

QDASH results were high in patients whose duration of the disease was $>6$ years and in patients with severe clinic symptoms. Also, in a correlation analysis, we found a positive correlation between disease duration and clinical severity with QDASH results. However, no relationship between the electrophysiological level and QDASH results was found.

Itsubo et al. have applied preoperative and postoperative QDASH disability scale to patients with CTS but they did not find any relationship between electrophysiological findings. They reported a correlation with QDASH results and clinical severity in patients who were evaluated postoperatively - in this study, similar results were obtained. ${ }^{17}$ In addition, in various studies, it was stated that there was no relationship between scales that were used to evaluate symptom severity and functional status in CTS and electrophysiological findings. ${ }^{17-19} \mathrm{Chan}$ et al. did not find any relationship between symptom severity and functional status with electrophysiological findings in patients with mild CTS. They reported that all of the tests were required to be applied in evaluation of CTS. ${ }^{18}$ Longstaff et al. did not find any correlation between symptom severity and electrophysiological findings in patients with CTS who underwent a preoperative and postoperative scan retrospectively. ${ }^{19}$ De Campos et al. reported that in CTS, paresthesia, disability and nocturnal symptoms were not associated with electrophysiological findings. ${ }^{20}$

Electromyogram (EMG) is the most sensitive test for the diagnosis of CTS. In the literature, it is reported that the sensitivity of the median nerve studies ranges from 49 to $84 \%$, its specificity from 95 to $99 \% .{ }^{6}$ However, as stated above, in the studies, no correlation was found between sensory symptom severity and electrodiagnostic data in CTS. This is mainly because in electrophysiological studies, thick myelinated $A \beta$ fibers are evaluated. However, pain and paresthesia symptoms are related to the thin myelinated $A \delta$ fibers, neuropathic pain is located in the unmyelinated $C$ fibers. Thin and thick myelinated fibers are affected at different stages of CTS. Thin fibers are affected in the early stages of the illness. Another reason for the lack of correlation between sensory symptom severity and electrodiagnostic findings is the central sensitization and plasticity that is triggered by abnormal median nerve imputes. ${ }^{21}$ In clinical studies, laser-evoked potentials, sympathetic skin responses and quantitative sensory tests show that thin fibers were affected in CTS. However, no relationship was detected with electrophysiological data. ${ }^{21}$ Skin biopsy is the gold standard for demonstrating the affection of thin fibers. Recently, Schmind et al. found a reduction in the density of intra-epidermal fibers in CTS histopathologically, and it has been reported that there was no correlation between this result and electrophysiological findings. ${ }^{22}$

In other studies, it is suggested that in CTS symptom pathogenesis $\mathrm{C}$-fibres are not effective but $\mathrm{A} \delta$ fibers play an important role, and in CTS a correlation was reported between spontaneous pain intensity and $\mathrm{A} \delta$ fiber function. ${ }^{21,23}$ In our study, we found a mild correlation in the duration of the disease, clinical symptom severity and QDASH values with VAS scores that evaluated pain severity. Similarly, Koldas et al. reported moderate correlation between VAS and QDASH in their CTS QDASH Turkish version reliability and validity study. ${ }^{10}$ Imaeda et al. found a correlation between VAS and QDASH in the validity and reliability study of QDASH scale. ${ }^{24}$ Recently, Yücel et al. reported that QDASH was well correlated with pain and paresthesia, and they suggested that QDASH questionnaire appears to be more practical for carpal tunnel release patients. ${ }^{25}$ Although VAS values were found high in the patients with severe electrophysiological findings, we did not find a correlation between electrophysiological severity level and VAS. 
As a result, we found that in patients with CTS, QDASH values were related with clinical severity and the duration of the disease. Although we found a positive correlation between clinical severity level and EMG results, there was no corelation between QDASH results and EMG results. These findings are consistent with the inconsistencies between symptoms in CTS and electrophysiological data that was previously reported in the literature. However, in the clinical follow-up and treatment strategies of CTS patients, clinical, electrophysiological findings and patient-centered assessment scales should be considered together. Despite the electrophysiological findings, we think that individual differences are effective, while their clinical and functional capacities are being evaluated. We are of the opinion that QDASH scale can be applied in a short time and can easily be used for patients with CTS to evaluate the symptom severity and disability.

\section{References}

1. Atroshi I, Gummesson C, Johnsson R, Ornstein E, Ranstam J, Rosén I. Prevalence of carpal tunnels syndrome in a general population. JAMA. 1999;282(2):153-158.

2. Tanaka S, Wild DK, Seligman PJ, Behrens V, Cameron L, Putz-Anderson $\mathrm{V}$. The US prevalence of self-reported carpal tunnel syndrome: 1988 National Health Interview Survey data. Am J Public Health. 1994;84(11):1846-1848.

3. Zanette G, Marani S, Tamburin S. Extra-median spread of sensory symptoms in carpal tunnel syndrome suggests the presence of pain-related mechanisms. Pain. 2006;122(3):264-270.

4. Zanette G, Marani S, Tamburin S. Proximal pain in patients with carpal tunnel syndrome: A clinical-neurophysiological study. J Peripher Nerv Syst. 2007;12(2):91-97.

5. Zanette G, Cacciatori C, Tamburin S. Central sensitization in carpal tunnel syndrome with extraterritorial spread of sensory symptoms. Pain. 2010;148(2):227-236.

6. ArooriS, Spence RA.Carpal tunnel syndrome. UlsterMedJ.2008;77(1):6-17.

7. Rempel D, Evanoff B, Amadio PC, et al. Consensus criteria for the classification of carpal tunnel syndrome in epidemiologic studies. Am J Public Health. 1998;88(10):1447-1451.

8. Hudak P, Amadio PC, Bombardier C. Development of an upper extremity outcome measure: The DASH (disabilities of thearm, shoulder and hand). The Upper Extremity Collaborative Group (UECG). Am J Ind Med. 1996;29(6):602-608.

9. Duger T, Yakut E, Oksuz C, Yurukan S, Bilgutay BS, Ayhan C. Reliability and validity of the Turkish version of Disabilities of the Arm, Shoulder and Hand (DASH) Questionnaire. Fizyoterapi Rehabilitasyon. 2006;17:99-103. [in Turkish]

10. Koldas Dogan S, Ay S, Evcik D, Baser O. Adaptation of Turkish version of the questionnaire Quick Disability of the Arm, Shoulder, and Hand (Quick DASH) in patients with carpal tunnel syndrome. Clin Rheumatol. 2011;30(2):185-191.

11. AAN, AAEM, AAPMR. Practice parameter for carpal tunnel syndrome (summary statement). Report of the Quality Standards Subcommittee of the American Academy of Neurology. Neurology. 1993;43(11):2406-2409.

12. Padua L, Lo Monaco M, Padua R, Gregori B, Tonali P. Neurophysiological classification of carpal tunnel syndrome: Assessment of 600 symptomatic hands. Ital J Neurol Sci. 1997;18(3):145-150.

13. Padua L, Padua R, Lo Monaco M, Aprile I, Tonali P. Multiperspective assessment of carpal tunnel syndrome: A multicenter study. Italian CTS Study Group. Neurology. 1999;53(8):1654-1659.

14. Leventoğlu A, Kuruoğlu R. Do electrophysiological findings differ according to the clinical severity of carpal tunnel syndrome? J Neurol Sci. 2006;23(4):9:272-278.

15. Preston DC, Schapiro BE. Electromyography and neuromuscular disorders. Clinical-electrophysiologic correlations. $2^{\text {nd }}$ ed. Pennsylvania: Elselvier Health Sciences; 2005.
16. Ibrahim I, Khan WS, Goddard N, Smitham P. Carpal tunnel syndrome: A review of the recent literature. Open Orthop J. 2012;6:69-76.

17. Itsubo T, Uchiyama S, Momose T, Yasutomi T, Imaeda T, Kato H. Electrophysiological responsiveness and quality of life (QuickDASH, CTSI) evaluation of surgically treated carpa tunnel syndrome. J Orthop Sci. 2009;14(1):17-23.

18. Chan L, Turner JA, Comstock BA, et al. The relationship between electrodiagnostic findings and patient symptoms and function in carpal tunnel syndrome. Arch Phys Med Rehabil. 2007;88(1):19-24.

19. Longstaff L, Milner RH, O'Sullivan S, Fawcett P. Carpal tunnel syndrome: The correlation between outcome, symptoms and nerve conduction study findings. J Hand Surg Br. 2001;26(5):475-480.

20. De Compos CC, Manzano GM, Leopoldino JF, et al. The relationship between symptoms and electrophysiological detected compression of the median nerve at the wrist. Acta Neurol Scand. 2004;110(6):398-402.

21. Tamburin S, Cacciatori C, Praitano ML, et al. Median nerve small- and large-fiber damage in carpal tunnel syndrome: A quantitative sensory testing study. J Pain. 2011;12(2):205-212.

22. Schmid AB, Bland JD, Bhat MA, Bennett DL. The relationship of nerve fiber pathology to sensory function in entrapment neuropathy. Brain. 2014;137(Pt 12):3186-3199.

23. Truini A, Padua L, Biasiotta A, et al. Differential involvement of A-delta and $A$-beta fibres in neuropathic pain related to carpal tunnel syndrome. Pain. 2009;145(1-2):105-109.

24. Imaeda T, Toh S, Wada T, et al. Impairment Evaluation Committee, Japanese Society for Surgery of the Hand. Validation of the Japanese Society for Surgery of the Hand Version of the Quick Disability of the Arm, Shoulder, and Hand (QuickDASH-JSSH) questionnaire. J Orthop Sci. 2006;11(3):248-253.

25. Yücel H, Seyithanoğlu H. Choosing the most efficacious scoring method for carpal tunnel syndrome. Acta Orthop Traumatol Turc. 2015;49(1):23-29. 